\title{
An Investigation of Air Flow and Thermal Comfort of Modified Conventional Car Cabin using Computational Fluid Dynamics
}

\author{
S. Ibrahim $^{1 \dagger}$ and R. C. Mehta ${ }^{2}$ \\ ${ }^{1}$ Department of Mechanical Engineering, Noorul Islam Centre for Higher Education, Kumaracoil, Thuckaly, \\ Tamil Nadu, India \\ ${ }^{2}$ Faculty of Aeronautical and Space Technology, Noorul Islam Centre for Higher Education, Kumaracoil, \\ Thuckaly, Tamil Nadu, India
}

†Corresponding Author Email: ibrahimshamim188@gmail.com

(Received May 15, 2018; accepted July 18, 2018)

\begin{abstract}
Air conditioning is widely used in many areas to reduce the heat and humidity of the work place and to maintain a room temperature for thermal stability and physical ability to perform various tasks. Computational Fluid Dynamics (CFD) is based on the numerical solutions of the fundamental governing equations of fluid dynamics namely the continuity, momentum and energy equations. Computerized fluent mechanics is one of the increasing paradigm in the air flow simulation in vehicle designs. The design optimization of vehicle can offer better efficiency in cabin surface as well as aerodynamic. In vehicles, air conditioning tends to offer efficient thermal conditioning and air circulation inside the cabin for passenger comfort from different climate variation. Almost all the automobiles available in the market are fitted with air-conditioning systems. The manufacturers focus clearly on the AC system for a wide variety of climates. As technology advances, AC system is also adhering major advancements. In general, automobile airconditioning systems are designed to provide comfort for the driver and the passengers during a journey. The conventional electrical-driven compression systems are widely used in almost all of the automobiles today. An air-conditioner is operated to make a hot and humid passenger compartment a more comfortable environment. However, with the improvement in vehicle fuel economy, the allowable power consumption for the air-conditioner has been decreasing, in relation to the overall power consumption of the vehicle. The internal temperature-humidity conditions are an essential factor for the comfort and health of passengers, and also for the safety of drivers. In this research, the air conditioning inside vehicle cabin is analyzed. The objective of the research is to develop an air depression design inside the top surfaces of the rear cabin. The optimal flow of air inside cabin increases the thermal comfort of the vehicle. The proposed cabin depression design inside the rear top surfaces are analyzed under thermal variation and airflow circulation inside the cabin. The Ansys fluent tool is utilized in this paper to evaluate the variation of air flow and the temperature inside the passenger vehicle cabin respectively. From the research analysis, the proposed evaluation of the depression design is more optimal for air conditioning in budgetary small passenger vehicles.
\end{abstract}

Keywords: Automobile; Air conditioning; Humidity; Air duct; Temperature; Vehicle cabin; ANSYS Fluent.

\section{INTRODUCTION}

In today's modern world, the environment are undergone to pollution by the hasty activities handled by the humans and also in one or another act humans are playing a vigorous role in polluting the surrounding, as it may leads to the destruction of the ecosystem. At present, the entire society is in the lap of dealing with conservation of the nature. Subsequently, the environmental awareness and conservation of the energy are tempt to be one of an adequate factor that are responsible for the enlargement of the distinct sectors. Automobile industries are intent to mold some pollution-free vehicles on behalf of saving the environment by getting polluted. The reason behind the increase in air conditioned vehicles are the relative effect in humidity and the climatic variations respectively (Pang et al., 2012). Similarly, based on the thermodynamic and psychometric survey it is evidently proven that the relative humidity can expedite the process of air conditioning and decrease the energy deduction. Moreover, the 
transformation will leads to a hold up from the customer satisfaction. Thereby the customer will get satisfied only when he/she feels a warmth by using the commodity (Baskovic et al. 2014). Accordingly, thermal comfort is accounted as one of an efficient factor which depends on the conduction, radiation, and heat loss carried out by the evaporation.

Henceforth, for satisfying and meeting all the needs in the present case an absolute mechanism has been proposed in this paper namely CFD influenced Ansys Fluent tool has been used to cure all the upcoming issues in the field. The requirement of comfort and safety are large except by the consumer from the manufacturers, the need for air conditioning is mostly considered for future generation of vehicles such as electric and hybrid vehicles. Considerably, the modern systems are featured with integrated cooling, heating, demisting, de-frosting, air filtering, and humidity control. By the utilization of the corresponding techniques can improve the security of passenger and thereby in different environmental condition the windows in the vehicles can be closed to stay comfortably inside the cabin temperature. The newly established high-efficient air conditioners are particularly critic to the success of hybrid, fuel cell, and electric vehicles that have little power to spare (Kamar et al. 2012). The result is the newly developed IC engines are less pollutant and generate less heat to the passenger for heating. In the proposed tool, the air conditioning technology is designed with heat pumps for generating heat to the passenger for cold seasons and used as defogger for windows from frosting in summer seasons (Khaled et al. 2012). Manufacturers are designing new systems with high cooling performance and reliability, operational and service safety, environmental performance, and serviceability. Global co-operation under the partnership speeds the development and commercialization of its test program, and standards work. Researches were vastly developed for the generation of new air conditioning systems which diminishes the impacts on the environment and satisfy the requirements of customer's safety and comfort at consistent standards (Singh \& Bartaria, 2015). With an increase in the thermal comfort for passenger cabins and intelligent driving for easy driver control and convenience, many smart and green passenger vehicles have been developed and researched by various automotive makers. Also, advanced automotive technology, with the modernization of the transportation industry, seeks to improve the comfort and convenience of the driver.

Numerous air conditioning systems are developed for advanced cooling and heating inside the vehicle cabin. Researches were carried out to improve the cabin thermal comfort and air condition for the passengers in the vehicles (Quadri \& Jose. 2013). Optimizing the A/C air flow system design can significantly reduce the mass and volume of current $\mathrm{A} / \mathrm{C}$ systems in various vehicles, and impact the $\mathrm{A} / \mathrm{C}$ system control strategy, in satisfying cabin thermal comfort requirements. However, genuinely optimizing the air flow duct of $\mathrm{A} / \mathrm{C}$ system design is complicated by the transient nature of the system performance and its inherent coupling to cabin thermal conditions (i.e., heat loads, air temperatures, vent configurations, etc.). The $\mathrm{A} / \mathrm{C}$ system pressures, temperatures, and condenser and evaporator flow conditions are all time-dependent (Chimakurthi et al. 2018). They are controlled by transient compressor speed, refrigerant and air flow rates, and vehicle thermal loads. Refrigerant and airflow rates are, in turn, determined by vehicle velocity and compressor speed. In any system optimization, it is essential to perform a comprehensive search of the variable design space to locate the optimum solution (Piovano et al. 2016). The performance of the concerned product can be empowered faster by inducing a power packed computational fluid dynamics (CFD) tool named ANSYS Fluent software respectively. The proposed tool consist of a well-validated capability of physical modelling to deliver more accurate and faster result on the basis of a multi-physical application across the CFD range. In ANSYS Fluent tool, the shape of the free surface in the ink droplet is captured by the influence of the VOF (Volume of Fluid) approach and also it models the surround air outside the nozzle. The Fluent model will induce the surface tension and the wall adhesion effect respectively. Model development continues to increase the analytic power and flexibility, while the Solid Work model has integrated within ANSYS Fluent analysis software can evaluate regarding the real-time application. Thus by analyzing the optimized air flow depression on cabin surfaces can enhance the efficiency of air conditioning system and energy consumption in passenger vehicles (Sun et al. 2016).

The contribution of the whole paper is scripted in the following manner. Initially, the past literature survey for the research is elaborated and section 2 will discuss the proposed design for the investigation of the air flow in vehicle cabin is defined in section 3 respectively. Subsequently, the experimentation and analysis results are elaborated in section 4. Finally, the conclusion of the research methodology is defined in section 5 respectively.

\section{LITERATURE SURVEY}

Air conditioning systems are utilized as a part of various stationary and remote applications to give comfort to residents or suitable temperature and humidity for passengers in vehicles. Huge air conditioning and cooling system require improvement of the depression design to limit the aggregate cost, which incorporates the underlying expense of the structure and the lifetime of the operational cost (Sun et al. 2016). To give the travelers in an auto with an agreeable lodge, the car air conditioning $(\mathrm{A} / \mathrm{C})$ unit should deal with obnoxious impacts of temperature, humidity, and air flow and heat radiation. To perform this undertaking, the $\mathrm{A} / \mathrm{C}$ unit needs to cool and heat air, dehumidify and allow the air to flow legitimately in various parts of the vehicle cabin, by controlling through four individual parts; an air flow mode 
selector, a blower, cooler and heater (Stoll et al. 2016). Most vehicles utilize a ventilating framework to enhance thermal solace in the compartment. The air conditioning system makes a thermally agreeable condition by controlling air temperature, stickiness, and indoor air quality. Myoung Su et al. (Yang et al. 2009) examines the thermal comfort in the vehicle compartment with the front and roof vents utilizing computational fluid dynamics with observational relationships for thermal indices. Also, the execution of the air conditioning unit was measured at different air flow rates and temperatures. From the outcome, it demonstrates the vitality utilization of the confined air conditioning framework with the advanced front and roof vents reduced during the investigation.

Temperature dissipation is a critical issue which is improved during the ideological duration of the framework. Improved temperature movement is basic utility for the comfort of the passengers and must be accomplished with high resilience. For instance, the face outlet needs more temperature than the foot outlet or cooled outlet (Sukri et al. 2016). So the wind stream must be guided such that these necessities have met. Scholars and designers have widely examined the thermal comfort conditions in the vehicle cabin for quite a long time. Conventional CFD models give exact recreation after effects of the air temperature diffusions inside the cabin at a moderately high calculation cost (Singh et al. 2016). To reduce the computational cost while providing sensible precision in reproducing the air temperature profile inside an averagely sized car cabin, Ling et al (Mehta et al.2016) proposes another reproduction device that uses an appropriate orthogonal decomposition (POD) strategy. The POD strategy is to anticipate the air temperature profile inside a car cabin considered as an optional way to deal with the conventional CFD technique. The outcomes demonstrate that the time expended for the investigation is lower than the regular examination procedure. Maintaining thermal comfort is one of the key regions in vehicle HVAC plan wherein wind stream conveyance inside the cabin is one of the vital components in choosing comfort response. This examination ponder concentrates on the numerical investigation of cabin pointing and lodge chill off in a traveler vehicle by utilizing computational fluid dynamics (CFD). Sen et al (2016) explore the cabin pointing to make sense of the base normal speed over the travelers at all vent positions. Cabin pointing guarantees a considerable measure of air flow spans to the travelers and in addition each edge of the lodge over the wide climatic range. The numerical expectation of stream field, cabin cooling rate was additionally approved with that of a test outcome, it is exceptionally valuable apparatus to use at the beginning time of configuration cycle to upgrade the HVAC structure as far as performance, improvement time and cost.

Subsequently, as discussed before the air is first absorbed through the inlet vents where it will filter the different contaminants. Air flows initiate from a high-pressure segment to a low weight segment. The air is then distributed to various parts of the system in return amount with the assistance of entryways and air designs. An air direct is a section which controls the air into a specific segment of the framework and is intended to accomplish the direction. Passenger thermal comfort and lowering in energy utilization due to expanding price of energies is a significant paradigm in configuration phase of a passenger vehicle. Ajay Giri et al. (Giri et al. 2017) explored the air flow and temperature circulation in the cabin of a vehicle with various vent speeds considering an inlet vent in front and an outlet in the back of the vehicle. Temperature dispersion improves with increment in the channel speed, and general cabin temperature is diminished with giving vent in the cabin. In this manner, the examined results prove that the air flow and temperature diminishment in the compartment could be more effective with the consistent air vent design.

A collection of investigations have reported the perilously high temperatures that may happen inside the passenger cabin of the vehicle under clear environmental conditions, even at moderately low ambient air temperatures. Grundstein et al. (2009) look at cabin temperatures under variable climate conditions. This examination considers measuring the impact of various encompassing air temperatures and solar powered radiation values on vehicle cabin temperatures. It utilizes a one of a kind most extreme cabin temperature dataset that is connected with meteorological information on encompassing air temperatures, solar radiation, and cloudy condition. The proposed models and records can be utilized for gauging risky conditions, awareness of public responses, and to evaluate past cabin temperatures for use in experimental researches. With dynamic changes in vehicle styling, fixing efficiency imperatives, the substitution of the naturally hazardous refrigerants and relating diminishments in the thermal convenient for the passenger heating system. There is enthusiasm for the advancement of more successful heating, ventilating, and air conditioning (HVAC) system to guarantee passengers thermal comfort even in extraordinary conditions by considering market circumstance. Sevilgen et al. (Sevilgen, \& Kilic 2012) demonstrated a 3-D vehicle cabin including window and external surfaces was displayed by utilizing the accurate measurements of a vehicle. The outcome acquired by temperature appropriations of the car cabin of 3D steady and transient numerical investigations for a standard period of heating and cooling. Godwin (2017) and Lakshmanan (2017) investigated about the optimum parameters for obtaining the best performance using alternate fuels of IC engines working under the current cooling system using Nanofluids. Srinivasan (2017) studied and analysed about the missile with grid fins and the effect on flow drag using ANSYS.

\section{CFD INVESTIGATION OF AIR CONDITIONING IN SMALL PASSENGER VEHICLES}

Air-conditioning is one of the essential parameters in most vehicles for enhancing the passenger comfort and safety. Usually, air vents in passenger car have a manual adjustment of the vanes to set the 
airflow direction. The purposes of a vehicle cabin are to provide a thermally comfortable environment for the driver and passengers. Designing of efficient air distribution system in vehicles such that airflow over the particular part of the body can remove excess of heat. Air flow and temperature distribution in an air-conditioned car change according to the various human loads. The air flow inside the vehicle is directed to a small section due to the limited space of a car. The air flows from air conditioning vents increases the air velocity, and it will be blocked by the front and rear seats and forms re-circulating flow patterns.

This research paper can give a clear analyzed study to improve the airflow in vehicle cabin and thereby to increase the air conditioning of the vehicle. This paper proposes an airflow depression which is optimal for the continuous airflow in front and rear side of the cabin. The methodology starts with a design procedure of cabin with an aerodynamic projection on the roof surface of the rear passenger side. These projections lead the airflow continuously circulated to the passenger seated on the rear side. The air flow of vehicle is analyzed at different pressure limits with solar radiation and simulated in the real-time scenario by Ansys Fluent software, where the Solid Works created the geometry model of the cabin Solid Works and extracted to mesh for the evaluation of temperature variation and air flow inside the vehicle cabin. From the simulation results, it explains the air flow in the proposed depression design has less temperature coefficient than existing model and can attain optimal air conditioning in the small vehicle cabin.

\subsection{Experimental Setup}

The experimentation is carried out in the following passenger vehicle with the following analyzing parameters given in table 1 .

Table 1 Parameters for Analysis

\begin{tabular}{|c|c|c|c|}
\hline & $\begin{array}{c}\text { Inner } \\
\text { Surface }\end{array}$ & $\begin{array}{c}\text { Outer } \\
\text { Surface }\end{array}$ \\
\hline \multirow{3}{*}{$\begin{array}{c}\text { Cabin } \\
\text { Dimen } \\
\text { sion }\end{array}$} & Length (m) & 1.03 & 1.13 \\
\hline & $\begin{array}{c}\text { Width } \sim \mathrm{L} / 2 \\
(\mathrm{~m})\end{array}$ & 0.76 & 0.56 \\
\hline & Height (m) & 1.15 & 1.21 \\
\hline \multicolumn{2}{|c|}{ Solar Intensity $\left(\mathrm{W} / \mathrm{m}^{2}\right)$} & $500-800$ & $500-800$ \\
\hline \multicolumn{2}{|c|}{ Temperature $\left({ }^{\circ} \mathrm{C}\right)$} & 16 to 25 & 30 to 38 \\
\hline \multicolumn{2}{|c|}{ Air Velocity (m/s) } & 0.1 to 0.5 & 0.1 to 0.5 \\
\hline \multicolumn{2}{|c|}{ Air Vents } & 4 (inlet) & 2 (outlet) \\
\hline \multicolumn{2}{|c|}{ Air Pressure (bar) } & 1 to 5 & 1 to 5 \\
\hline
\end{tabular}

\section{i) Free Convection}

Free convection develops from the thermal uncertainties, and numerous uncertainties also arise such as hydrodynamic uncertainties related to the transition between a laminar flow to the turbulent flow. The flow characteristics are categorized into laminar (or) turbulent and act as thermal convection between the object and walls. The viscosity of the air is very thin. Hence it does not pass relative to the wall which makes an increase in velocity from zero to maximum at the wall and decreases when reaching the uniform air temperature. The initial wall temperature $T_{w}$ drops with the room temperature $T_{\infty}$ from the wall distance. The free convection is practiced for the constant temperature wall, and there is an increase of small temperature, and the air moves upward. Therefore the rise in temperature causes heat transfer to the upward direction. For the condition of a high wall, the flow changes from laminar to turbulent flow. The increase of temperature in boundary layer near the wall cause heat transfer in the wall surfaces. In case of a high wall, the flow varied from laminar to turbulent, and the convection is complicated one delicate with high accuracy. Therefore the convection rule for evaluating the heat transfer in the wall surface can be derived from the following equation. The essential components of heat transfer by convection mechanisms are given in Newton's law of cooling in equation (1).

$$
Q=h \cdot A \cdot\left(T_{w}-T_{\infty}\right)
$$

Where, $Q$ is the rate of heat transferred between the exposed surface $A$ of the wall and the fluid. $T_{w}$ is the temperature of the wall, $T_{\infty}$ is the temperature of the free stream of air, $h$ is the convection coefficient. Moreover, the convection coefficient is not uniform on the entire surface, and it also depends on the location where the temperature of the fluid ' $Q$ ' is evaluated. In most cases, it is therefore convenient and practical to use average values for the convection coefficients.

\section{ii) Quantities Used in Convection Coefficient Evaluation}

The occurrence of laminar (or) turbulent flow is usually correlated with Rayleigh number, which is simply the product of the Grashof and Prandtl numbers. The following equation gives Grashof number for convection.

$G r=\frac{L^{3} \cdot g \cdot \beta \cdot\left(T_{w}-T_{\infty}\right)}{v^{2}}$

Where, $L$ is the characteristic length of the surface in meter, $g$ is gravity in $m / s^{2}, \beta$ is the thermal expansion coefficient in $1 / K, v$ is the kinematic viscosity in $\mathrm{m}^{2} / \mathrm{s}, \quad T_{w}$ is the outer surface temperature and $T_{\infty}$ is the inner surface temperature at ambient condition.

All fluid characteristics (such as density, kinematic viscosity, Prandtl number, thermal diffusivity etc.) are evaluated at film temperature. Therefore, the film temperature of the surface can be evaluated by the following equation. 
$T_{f}=\frac{T_{w}+T_{\infty}}{2}$

For ideal gases, $\beta=\frac{1}{T_{f}}$ while for liquids and nonideal gases the expansion coefficient must be obtained from appropriate property tables. Prandtl number is the ratio of two molecular transport properties, the kinematic viscosity $V$ which affects the velocity profile and the thermal diffusivity $\alpha$, which affects the temperature profile and $k$ is the fluid thermal conductivity in $W / m K, C_{p}$ is the fluid specific heat in $\mathrm{J} / \mathrm{KgK}$.

\section{iii) Thermal Convection inside the Cabin Surface}

At $T_{f}=309 \mathrm{~K}$ the air properties are

$$
\begin{aligned}
& v=4.6 \times 10^{-5} \mathrm{~m}^{2} / \mathrm{s} \\
& \alpha=6.7 \times 10^{-5} \mathrm{~m}^{2} / \mathrm{s} \\
& \operatorname{Pr}=0.69 \\
& \beta=\frac{1}{T_{f}}=3.23 \times 10^{-3} \mathrm{~K}^{-1} \\
& k=0.0431 \mathrm{~W} / \mathrm{m}
\end{aligned}
$$

From the constraints taken for the temperature of the air, the Rayleigh number can be calculated from the given equation.

$$
R_{a}=2.62 L^{3}
$$

Where, $R_{a}$ is the Rayleigh number, $C$ and $n$ are drag coefficients. Typically, $n=1 / 4$ for laminar flow and $n=1 / 3$ for turbulent flow. For turbulent flow, $R_{a}>10^{9}$, for laminar flow $R_{a}<10^{9}$. Thus the convection is considered separately from the sides as well as the other two horizontal surfaces (top and bottom). Then the Rayleigh number for the convection is calculated from the equation (4) respectively. For most engineering calculations, the convection coefficient is obtained from a relation of the form. Therefore, the Nusselt number is evaluated by the given equation as follows.

$\bar{N} u=\frac{\bar{h}_{\text {in } / \text { out }} \cdot L}{k}=C \cdot R_{a}^{n}$

Where, $C$ is the drag coefficient of air at 1.05 and $R_{a}^{n}$ be the Rayleigh number for laminar flow at $n=1 / 3$.

For the two sides, $L=H=1.03 \mathrm{~m}$ which yields $R_{a}=2.862$ corresponding to a laminar flow in the boundary layer. The heat convection to the inside side surfaces can be calculated from the following equation (6).

$$
\bar{h}_{i n}=\frac{k}{H} \cdot \bar{N} u
$$

$\bar{h}_{i n}=\frac{k}{H}\left\{0.68+\frac{0.67 \times\left(R_{a}\right)^{1 / 4}}{\left[1+(0.496 / \mathrm{Pr})^{9 / 16}\right]^{4 / 9}}\right\}$

$\bar{h}_{i n}=\frac{0.0431}{1.03}\left\{0.68+\frac{0.67 \times(2.862)^{1 / 4}}{\left[1+(0.496 / 0.69)^{9 / 16}\right]^{4 / 9}}\right\}$

$\bar{h}_{i n}=0.0534 \mathrm{~W} / \mathrm{m}^{2} \mathrm{~K}$

For the top and bottom surfaces with $L \approx w / 2=0.72 m$ and therefore Rayleigh number, $R_{a}=0.977$. Therefore, the convection coefficient for the top and bottom surfaces can be evaluated by the following equations (10) and (11).

$$
\begin{aligned}
& \overline{\mathrm{h}}_{\text {top }}=\frac{\mathrm{k}}{\mathrm{w} / 2} \cdot 0.15 \cdot \mathrm{R}_{\mathrm{a}}^{1 / 3}=5.47 \times 10^{-3} \mathrm{~W} / \mathrm{m}^{2} \mathrm{~K} \\
& \bar{h}_{\text {bottom }}=\frac{k}{\mathrm{w} / 2} \cdot 0.27 \cdot R_{a}^{1 / 4}=9.87 \times 10^{-3} \mathrm{~W} / \mathrm{m}^{2} \mathrm{~K}
\end{aligned}
$$

The outside cabin temperature $T_{w}$ will be $313 \mathrm{~K}$ and room temperature $T_{\infty}$ inside the cabin said to be 289 $\mathrm{K}$. The Grashof number for the air flow inside the cabin at $313 \mathrm{~K}$ can be evaluated form the equation (2).

$$
G r=\frac{(1.03)^{3} \times 1.000 \times 0.0031 \times(319-315)}{\left(4.835 \times 10^{-5}\right)^{2}}
$$

$G r=5.87 \times 10^{6}$

Using Newton's law of cooling, heat transferred to the outside cabin temperature to the room cabin temperature can be calculated from the given equation (14).

$Q=\bar{h}_{i n} \cdot A \cdot\left(T_{w}-T_{\infty}\right)$

$Q=0.033 *(1.03 \times 0.72)(319-315)=1.58 \times 10^{5} \mathrm{~W}$

Thus, the heat convection on the inner surface of the cabin has an optimal temperature of cooling in the range of $1.58 \times 10^{5} \mathrm{~W}$.

\section{iv) Heat Convection outside the Cabin Surface}

Consider the cabin wall with a height of $L=1.13 \mathrm{~m}$ , width $W=0.56 \mathrm{~m}$ at outer cabin temperature, $T_{w}$ at $373 \mathrm{~K}$, the air temperature in the room $T_{\infty}$ is quiescent at $296 \mathrm{~K}$. The Rayleigh flow is turbulent at outside cabin for turbulent flow, $n=1 / 3$ respectively. Air properties are evaluated in thermal data at film temperature, $T_{f}=334 \mathrm{~K}$, are

$$
\begin{aligned}
& k=33.8 \cdot 10^{-3} \mathrm{~W} / \mathrm{mK} \\
& v=26.4 \cdot 10^{-6} \mathrm{~m}^{2} / \mathrm{s}
\end{aligned}
$$


$\alpha=38.3 \cdot 10^{-6} \mathrm{~m}^{2} / \mathrm{s}$

$\operatorname{Pr}=\frac{v}{\alpha}=0.69$

$\beta=\frac{1}{T_{f}}=0.0025 K^{-1}$

For the wall temperature of $334 \mathrm{~K}$, the properties of the cabin film temperature at $334 \mathrm{~K}$ are evaluated form the data table and the Rayleigh number for the wall temperature can be calculated from equation (4) and achieved at $R_{a}=3.780$, and follows transition to turbulent flow occurs on the wall. The following equations can evaluate the convection coefficient of the wall as below.

$$
\begin{aligned}
& \bar{N} u=\left\{0.825+\frac{0.387 \cdot R_{a}^{1 / 6}}{\left[1+(0.492 / \mathrm{Pr})^{9 / 16}\right]^{8 / 27}}\right\}^{2} \\
& \bar{N} u=\left\{0.825+\frac{0.387 \times(3.780)^{1 / 6}}{\left[1+(0.492 / 0.69)^{9 / 16}\right]^{8 / 27}}\right\}^{2}=0.989
\end{aligned}
$$

Therefore the convection coefficient for wall surfaces of cabin at $334 \mathrm{~K}$ will be

$$
\bar{h}_{\text {out }}=\frac{\bar{N} u \cdot k}{L}
$$

$\bar{h}_{\text {out }}=\frac{0.989 * 33.8 * 10^{-3} \mathrm{~W} / \mathrm{m} \cdot \mathrm{K}}{0.56}=0.059 \mathrm{~W} / \mathrm{m}^{2} \mathrm{~K}$

The outside wall temperature $T_{w}$ will be $373 \mathrm{~K}$, and room temperature $T_{\infty}$ inside the cabin said to be $296 \mathrm{~K}$. The Grashof number for the wall temperature to the room temperature is evaluated in the following equation. The Grashof number for the outside temperature of the cabin at $373 \mathrm{~K}$ can be evaluated form the equation (2).

$$
G r=\frac{(1.13)^{3} \times 1.000 \times 0.0025 \times(373-296)}{\left(26.4 \times 10^{-6}\right)^{2}}
$$

$G r=398.5 \times 10^{6}$

Using Newton's law of cooling, heat transferred to the wall to the room air can be calculated from the given equation (22).

$Q=\bar{h}_{\text {out }} \cdot A \cdot\left(T_{w}-T_{\infty}\right)$

$Q=0.059 *(1.13 \times 0.56)(373-296)=5.6 \times 10^{5} \mathrm{~W}$

The heat transferred to the wall surface of the outer cabin has lower temperature difference than the outer surface temperature in the range of $5.6 \times 10^{5} \mathrm{~W}$.

In table 2, the temperature variation inside the cabin has experimented with the mathematical model derived in the experimentation. The temperature of the cabin surface are evaluated based on the air pressure, velocity and temperature acting on the inner and outer surface of the vehicle cabin.

In Table 3, the experimental analysis is carried out in the mathematical model derived in the experimentation section. The analysis of cabin temperature is measured by the air flow pressure, velocity and temperature inside and outside of the vehicle cabin. Thus the temperature inside the cabin at various wall temperature and constant room temperature is analyzed.

\subsection{Numerical Modeling and Simulation}

The current research is to visualize numerically by thermal and fluid dynamic fields analysis inside the vehicle cabin for optimizing the design of air flow conditioning inside the vehicle cabin. The thermal analysis is conducted by incorporating the $3 \mathrm{D}$ model which has implemented in the design software for real-time analysis. To validate with real-time application, the model is numerically analyzed with external environmental conditions.

Table 2 Experimental Analysis of Temperature Variation in Existing Vehicle Cabin

\begin{tabular}{|c|c|c|c|c|c|c|c|c|}
\hline$P(P a)$ & $V(m / s)$ & $T_{w}(K)$ & $T_{\infty}(K)$ & $R_{e}$ & $\operatorname{Pr}$ & $G r$ & $\bar{h}_{i n}$ & $Q\left(W / m^{2} K\right)$ \\
\hline \multirow{5}{*}{$3 \mathrm{e}+7$} & 0.1 & 319 & 300 & 1.30 & 0.69 & $3.07 \mathrm{e} 5$ & 0.0513 & 0.722 \\
\cline { 2 - 9 } & 0.2 & 319 & 298 & 1.30 & 0.69 & $3.55 \mathrm{e} 5$ & 0.0502 & 0.781 \\
\cline { 2 - 9 } & 0.3 & 319 & 295 & 1.30 & 0.69 & $4.26 \mathrm{e} 5$ & 0.0490 & 0.871 \\
\cline { 2 - 9 } & 0.4 & 319 & 293 & 1.30 & 0.69 & $5.32 \mathrm{e} 5$ & 0.0454 & 0.874 \\
\cline { 2 - 9 } & 0.5 & 319 & 290 & 1.30 & 0.69 & $6.27 \mathrm{e} 5$ & 0.0442 & 0.949 \\
\hline
\end{tabular}

Table 3 Experimental Analysis of Temperature Variation in Proposed Cabin

\begin{tabular}{|c|c|c|c|c|c|c|c|c|}
\hline$P(P a)$ & $V(m / s)$ & $T_{w}(K)$ & $T_{\infty}(K)$ & $R_{e}$ & $\operatorname{Pr}$ & $G r$ & $\bar{h}_{i n}$ & $Q\left(W / m^{2} K\right)$ \\
\hline \multirow{5}{*}{$3 \mathrm{e}+7$} & 0.1 & 319 & 315 & 1.30 & 0.69 & $5.874 \mathrm{e} 6$ & 0.0534 & 0.1582 \\
\cline { 2 - 9 } & 0.2 & 319 & 312 & 1.30 & 0.69 & $1.479 \mathrm{e} 6$ & 0.0532 & 0.2759 \\
\cline { 2 - 9 } & 0.3 & 319 & 310 & 1.30 & 0.69 & $13.41 \mathrm{e} 6$ & 0.0530 & 0.3534 \\
\cline { 2 - 9 } & 0.4 & 319 & 305 & 1.30 & 0.69 & $21.32 \mathrm{e} 6$ & 0.0526 & 0.5456 \\
\cline { 2 - 9 } & 0.5 & 319 & 300 & 1.30 & 0.69 & $30.73 \mathrm{e} 6$ & 0.0513 & 0.7222 \\
\hline
\end{tabular}




\subsection{Governing Equations for Simulation}

The investigation has undergone a 3D model to simulate the passenger vehicle cabin by a transient thermal model. The thermal evaluation is undergone by the simulation on Ansys Fluent. The flow is analyzed under different thermal points, and the proposed cabin model gives optimal air flow density inside the cabin surface and to the passengers. In this turbulence model, the model has analyzed under viscous effect. In the following equation " $D / D t$ " is the derivative for the material and " $\nabla$ " is the average time quantities. In a viscous fluid, the surface boundary condition said to be no relative velocity between the surface and air flow at the surface. This condition is known as

the no-slip condition. For an inviscid fluid, the flow slips over the surface, and it will be tangential to the flow surfaces.

V. $\bar{V}=0$

Where, " $\bar{V} "$ is the surface unit vector perpendicular to the surface of the fluid. The surface boundary condition in the flow depends on the problem type is considered. It is to concern the inner and outer flow boundaries at very fine minute distance surfaces or an extended boundary condition far from the surfaces.

$$
\begin{aligned}
& \rho \frac{D \bar{V}}{D t}=-\nabla p+\rho(T) g+\nabla\left(\tau-\tau_{T}\right) \\
& \rho C_{p} \frac{D \bar{T}}{D t}=\nabla\left(q-q_{T}\right)
\end{aligned}
$$

The governing equation deduced from the fluid flow composed of highly non-linear and coupled partial differential equation systems. Particularly, the density " $q$ " is connected to the equation as a temperature function. The Boussinesq approximation is reflected as temperature density dependence. The appropriate boundary condition solves the rest of the equation. Since the flow is said to be turbulent, closure equation is required to arrive the solution. By using empirical data or perpetual models are used to define the turbulent stress in the related phenomenon of research criteria.

\section{EXPERIMENTAL ANALYSIS AND RESULT DISCUSSION}

The proposed technique has implemented in the working platform of ANSYS Fluent with the system specification.

Processor: Intel Core 2 Quad @ 2.5 GHz;

RAM: 3GB;

Operating system: Windows 7;

Simulation Software: Ansys Fluent 18.0;

Modelling Software: Solid Works.

\subsection{Design of Air Flow Depression on Cabin Surfaces}

Air-conditioning in the vehicle has mainly determined by the air duct orientation such as the increase of air vents, shape and position of air vents in the vehicle cabin. All budgetary passenger vehicle factory is fitted with four air vents on the dash board. However, the conditioning of passengers in front side is cooled/heated by the center mounted vents. However, in case of the rear passenger side, the vents mounted on the side of dashboards are utilized. Improving air conditioning performance and occupant thermal comfort requires an understanding of the fluid motion prevailing in the cabin for required ventilation setting and passenger loading. Airflow directivity inside a car is mainly influenced by the air duct orientation, the number of air vents, shape, and positions of the air vents inside the cabin. All cars come with a standard 4 outlet air vents on the dashboard. Normally, the center air vents are targeted to cool rear passengers, and the side air vents are for driver and co-driver. One of the ways to improve the airflow directivity inside the cabin is by making different shapes of the cabin with air depression. Newer vehicles were much more airtight than older vehicles, and this is a reflection upon the reduced weathering of door seals and other leakage pathways, as well as a likely improvement in design and manufacturing processes. The main problems facing recently is the rear side air conditioning of passenger. When comes to luxury vehicles, each side is provided with air-vents. However, in budgetary vehicles, the air conditioning is a concerning factor. To optimize these factors, the proposed research motivates to develop and design an efficient air depression shape upside to the rear passenger to make the air flow directed from the center air vent console. Thus the air conditioning becomes more efficient for the rear passengers. The following figure defines the cabin surfaces are modified from the vehicle conventionally air conditioned. The modification on the cabin surface is classified in the given figure 1 section.

\subsection{Mesh Generation}

The meshing process is generated in the model cabin to evaluate the thermal and air flow intensity inside the vehicle cabin. The meshing process is undergone by defining the boundary condition and structured the mesh in the passenger vehicle cabin. Considering that the far-divider work is demonstrated to influence the simulation accuracy less, an unstructured work is actualized for the passenger vehicle cabin model. The work is set to naturally catch the bends with better matrices as indicated by the radians. Moreover, better work is utilized for the surface of air vents. There are three layers of mesh at the limit, which gives better simulation exactness as indicated by the research of past area. The first point for the geometry is set at the mid-point of the interface between the surface below windshield and cabinet. It demonstrates that the mesh size is overwhelmed by the curve based refinement instead of the extensive component estimation. 

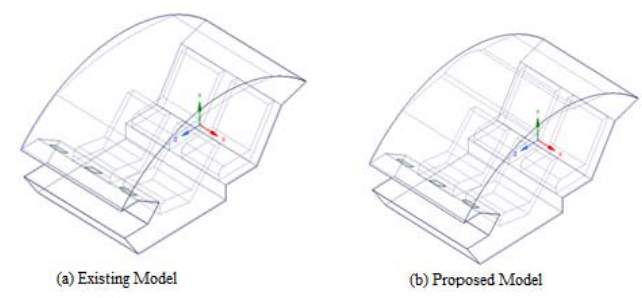

Fig. 1. Modifications on Vehicle Cabin

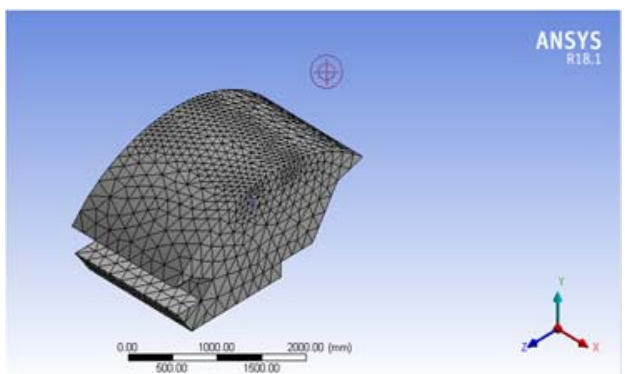

Fig. 2. Initializing Meshing on Cabin Model

\subsection{Numerical Simulation Analysis}

The simulation of the proposed geometry of the vehicle cabin is undergone with the Ansys Fluent Modelling with the parameters such as temperature and air flow respectively. The simulation results of the proposed modelling are highlighted in the following figures respectively. The numerical modelling is simulated in different phases. The model creation of vehicle cabin (dimension are extracted from current generation alto 800) by using Solid Works software. The model is extracted to ANSYS CFD where the model said to mesh under boundary conditions. The boundary condition is set according to various points of thermal diffraction and environmental conditions. The transient numerical examination was carried out on 3D vehicle cabin model which only incorporates the dimensional facility of the actual real dimension of the vehicle. This model creates just for the validation of air flow conditioning of vehicle cabin. The analysis is carried out by the CFD software, and the results have tabulated.

\subsection{Setting Boundary Conditions}

The CFD analysis carried out on the proposed vehicle cabin model is to examine the air flow and thermal condition inside the cabin surface under various boundary condition. To undergone certain level of simulation, boundary conditions are defined such as cabin temperature, pressure, cooling time and velocity of air vents for air conditioning etc. The initial air velocity has taken $8 \mathrm{~m} / \mathrm{s}$, and the temperature is said to $291 \mathrm{~K}$ respectively. Convective heat transfer as a boundary condition was taken from the top surface and wall surface of the vehicle cabin. Thermal radiation outside the cabin is by solar radiation in the range of $300 \mathrm{~W} / \mathrm{m}^{2}$ respectively.

In table 4 , the temperature inside the cabin surface is analyzed on front and the rear side, the simulated results of the proposed depression design cabin has lower temperature coefficient on front and rear side of the cabin than the existing conventional car cabin model respectively.

Table 4 Simulated Temperature of Cabin Surface

\begin{tabular}{|c|c|c|}
\hline Cabin Surface & \multicolumn{2}{|c|}{ Cabin Temperature (K) } \\
\hline & Proposed & Existing \\
\hline Front Side & 298 & 298 \\
\hline Rear Side & 302 & 303 \\
\hline Front Top & 301 & 301 \\
\hline Rear Top & 303 & 305 \\
\hline
\end{tabular}

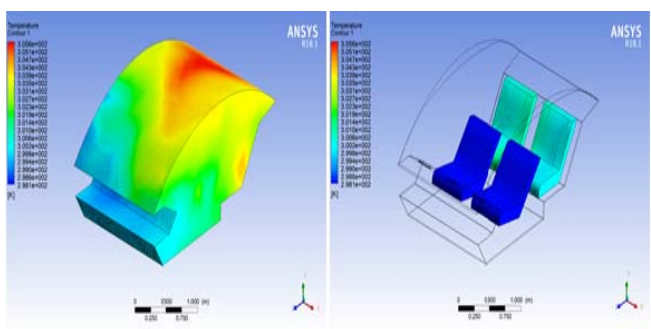

Fig. 3. Air Conditioning in Existing Vehicle Cabin

In figure 3 , the conventional small car cabin is modelled in a 3 dimensional way and simulated in Ansys CFD analysis. During the evaluation, the air comfort on the rear side of the passenger cabin obtains a lower rate than the cabin front side. The temperature on the rear side of the cabin has higher for each simulation runs. Thus the conventional cabin model has least air conditioning and forms less cooling comfort to the rear passengers.

In figure 4, the cabin surface of existing car cabin is modified with an efficient depression design to the top cabin surface of the rear passenger seat for efficient air flow in the area. The proposed depression design is more optimistic and new from the existing cabin model of the same vehicle with the same configuration. The incorporation of proposed depression design in the cabin has higher air flow to the rear side of the passenger cabin. Thus the proposed cabin depression design can be used as an efficient method for optimal air conditioning technique in small passenger vehicles respectively.
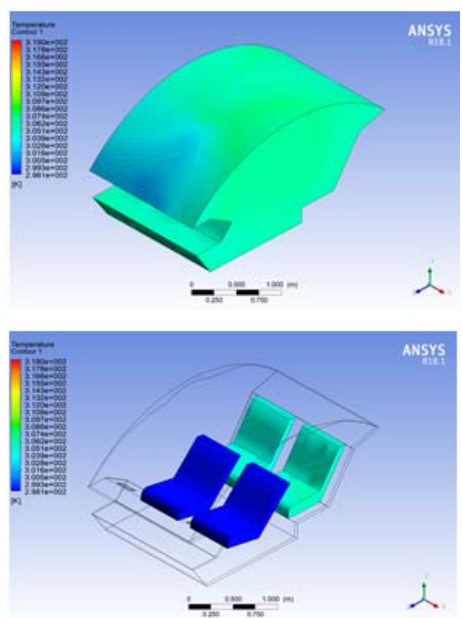

Fig. 4. Air Conditioning in Proposed Vehicle Cabin 
Table 5 Simulated Pressure and Temperatures

\begin{tabular}{|c|c|c|c|}
\hline \multirow{4}{*}{$P($ Pascal $)$} & $V(m / s)$ & \multicolumn{2}{|c|}{$Q\left(W / m^{2} K\right)$} \\
\cline { 2 - 4 } & & Proposed & Existing \\
\hline \multirow{3}{*}{$3 \mathrm{e}+7$} & 0.1 & $1.58 \mathrm{E}-5$ & $7.22 \mathrm{E}-5$ \\
\cline { 2 - 4 } & 0.2 & $2.75 \mathrm{E}-5$ & $7.81 \mathrm{E}-5$ \\
\cline { 2 - 4 } & 0.3 & $3.53 \mathrm{E}-5$ & $8.71 \mathrm{E}-5$ \\
\cline { 2 - 4 } & 0.4 & $5.45 \mathrm{E}-5$ & $8.74 \mathrm{E}-5$ \\
\cline { 2 - 4 } & 0.5 & $7.22 \mathrm{E}-5$ & $9.49 \mathrm{E}-5$ \\
\hline
\end{tabular}

In table 5, the air pressure inside the cabin for measuring the thermal stability and air conditioning of the vehicle. The pressure induced in the simulation initiates at a constant range of $3 e+7$ Pascal respectively. During the evaluation, the temperature at measured pressure difference has lower temperature coefficient for the rear side of the proposed cabin surface. Thus the modified depression form more optimal for air flow circulation in small passenger car cabin respectively.

In figure 5, the performance of temperature and air flow in the cabin surfaces are analyzed for the proposed cabin surface. The pressure of air induced in the vehicle cabin is in the constant range of $3 e+7$ Pascal respectively. During the evaluation, the temperature inside the cabin surfaces decreases when the flow of air circulated inside the cabin surfaces increases. Ultimately, the surface temperature of the proposed cabin design has optimal air conditioning than existing design. Hence, the results define the proposed cabin design can efficiently provide air conditioning in small conventional passenger vehicles respectively.

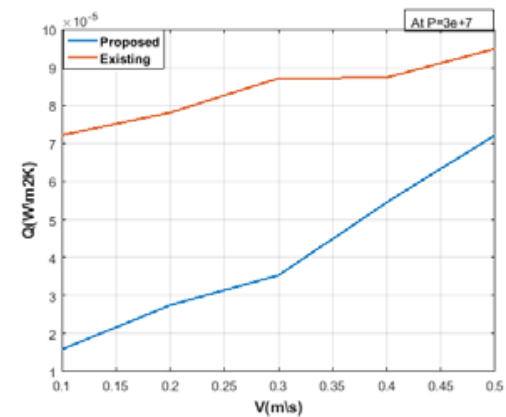

Fig 5. Performance Comparison of Cabin Surfaces

\section{CONCLUSION}

Air conditioning is primarily involved as the paradigm for passenger comfort in most economic vehicles for the last decades. The influence of effective thermal comfort and air flow inside the vehicle cabin is one of the research criteria throughout these years. In this research paper, effective air conditioning inside rear passenger area is analyzed. The analysis is carried out on small- sized passenger vehicle with air vents at the front side, by designing the effective depression design to the top surfaces of rear cabin significantly improves the air circulation to the rear passenger and cabin surfaces respectively. The work is extended by air depression design on the rear top surface of a conventional car by the solid works software and analyzed in Ansys fluent software at different temperature zones and air flows. From the simulation, the thermal comfort and air conditioning of the proposed cabin design vary at different temperature loads and air flow pressures. In this paper the overall simulations based on the air flow and the thermal conditional mechanism inside the surface of the concerned cabins which is being undergone by some specific conditions are carried out on the basis of the proposed CFD software. The Ansys Fluent, is considered as an effective practice that deals with the development of the continuous raise in the analysis of the flexibility and power of the model and also the tool is being influenced by the operation of the VOF. Subsequently the miniature will integrate the working of a solid development of the model on the real-time application. The CFD induce the Ansys Fluent tool to perform the Validation on the basis of the air flow occurrence in the cabin of the respective passenger vehicle. Fluent tool will also reduce the wall adhesion and surface tension in the optimal model. Thus, the simulation results indicate that the proposed air depression design can simultaneously optimize the air flow and temperature in conventional small passenger car cabin and improves the thermal comfort and air conditioning in small passenger car cabin respectively.

\section{REFERENCES}

Baskovic, U. Zvar, M. Lorenz, and V. Butala (2014) Adiabatic flow simulation in an airconditioned vehicle passenger compartment, International Journal of Simulation Modelling 13(1), 42-54.

Chimakurthi, S. Kumar, et al. (2018) ANSYS Workbench System Coupling: a state-of-the-art computational framework for analyzing multiphysics problems, Engineering with Computers $34(2), 385-411$.

Giri, A. et al (2017) Investigation of Air Circulation and Temperature Distribution in Car Compartment, International Advanced Research Journal in Science, Engineering and Technology 4(3).

Grundstein, A., V. Meentemeyer, J. Dowd (2009) Maximum vehicle cabin temperatures under different meteorological conditions, International Journal of Biometeorology 53(3), 255-261.

Kamar, H., M. Senawi, and N. Kamsah (2012) Computerized simulation of automotive airconditioning system: development of mathematical model and its validation, International Journal of Computer Science 9(2), 23-34. 
Khaled, M., et al. (2012) Fan air flow analysis and heat transfer enhancement of vehicle underhood cooling system-Towards a new control approach for fuel consumption reduction, Applied Energy 91(1), 439-450.

Levinson, R., H. Pan, G. Ban-Weiss, P. Rosado, R. Paolini, H. Akbari (2011) Potential benefits of solar reflective car shells: Cooler cabins, fuel savings and emission reductions, Applied Energy 88(1), 4343-4357.

Ling, J., et al. (2013) A new computational tool for automotive cabin air temperature simulation, SAE International Journal of Passenger CarsMechanical Systems 6(1) 841-846.

Mehta, A. and S. Singh. (2016) Comparative Analysis of Thermal Accumulation at Various Points inside a Car Cabin, Int J Adv Engg Tech 7(4), 15.

Pang, S. C., et al. (2012) A review on air flow and coolant flow circuit in vehicle's cooling system, International Journal of Heat and Mass Transfer 55(23), 6295-6306.

Piovano, A. Alessandro, L. M. Lorefice and G. Scantamburlo (2016) Modelling of Car Cabin Thermal Behaviour during Cool Down, Using an Advanced CFD/Thermal Approach, SAE Technical Paper, No. 2016-01-0213.

Quadri, Z. and J. Jose. (2013) Computational analysis of thermal distribution within passenger car cabin, Irdindia 2(2), 119-125.

Sen, S. and M. Selokar (2016) Numerical simulation and validation of cabin aiming and cool-down of a passenger car, SAE
International Journal of Passenger CarsMechanical Systems 9(1), 52-61.

Sevilgen, G., M. Kilic (2012) Three dimensional numerical analysis of temperature distribution in an automobile cabin, Thermal Science 16(1), 321-326.

Singh, M. and V. N. Bartaria (2015) CFD analysis of modified car air distribution system by changing supply and return air vents, International Journal of Advance Engineering and Research Development 2(4).

Singh, S., A. Mehta, and V. Gupta. (2016) Car Cabin Thermal Accumulation Analysis of at Various Points, International Journal of Scientific and Technical Advancements 2(4), 151-154.

Stoll, D. et al. (2016) Investigation of aerodynamic drag in turbulent flow conditions, SAE International Journal of Passenger CarsMechanical Systems 9, 733-742.

Sukri, M. F., et al. (2016) Modeling and Parametric Study of Cooling Loads Characteristics for Automotive Air-Conditioning System, Applied Mechanics and Materials 819(1), 189.

Sun, T., Q. Jiang, and P. Wang (2016) CFD-Based Modeling of Heat Transfer in a Passenger Compartment, Automotive Air Conditioning. Springer International Publishing 3-12.

Yang, J. H., S. Kato, H. Nagano(2009) Measurement of airflow of air conditioning in a car with PIV, Journal of Visualization 12(1), 119-130. 